\title{
Positron porosimetry study of mesoporous polymer-silica composites
}

\author{
Radosław Zaleski ${ }^{1} \cdot$ Marek Gorgol $^{1} \cdot$ Agnieszka Kierys $^{2} \cdot$ Jacek Goworek $^{2}$
}

Received: 15 October 2015/Revised: 13 January 2016/Accepted: 22 January 2016/Published online: 1 February 2016

(c) The Author(s) 2016. This article is published with open access at Springerlink.com

\begin{abstract}
The polymer-SiO ${ }_{2}$ composites prepared using polymers with different chemical composition and porosity (i.e. XAD4, XAD16, and XAD7) as well as series of composites synthesized with different contents of silica species and at different $\mathrm{pH}$ were investigated. The study was conducted to compare the results of nitrogen adsorption and positron porosimetry for these three sets of samples. The possible causes of the inconsistency between the results of both methods are discussed. The impact of the chemical character of the polymer support surface on the final properties of the polymer-silica composite was found to be greater than its porosity (i.e. the shape of pores and their connectivity). Changing the $\mathrm{SiO}_{2}$ content influences mostly the pore volume of composites. To significantly modify their pore size distribution, more than $30 \mathrm{wt} \%$ of silica species are required. The composite synthesized at $\mathrm{pH} 5$ has the widest pore size distribution among all samples supported by XAD7. The discrepancies concerning the porosity derived with both methods are the smallest for composites where XAD7 was used as the support. This allows determination of the relation $\mathrm{V}=(3.38$ $\left.\mathrm{V}_{\text {PALS }}-0.03\right) \mathrm{cm}^{3} / \mathrm{g}$, which may be useful for estimation of pore volumes corresponding to those found by nitrogen adsorption.
\end{abstract}

Radosław Zaleski

radek@zaleski.umcs.pl

1 Department of Nuclear Methods, Institute of Physics, Maria Curie-Skłodowska University, Pl. M. Curie-Skłodowskiej 1, 20-031 Lublin, Poland

2 Department of Adsorption, Faculty of Chemistry, Maria Curie-Skłodowska University, Pl. M. Curie-Skłodowskiej 3, 20-031 Lublin, Poland
Keywords Positronium lifetime - Nitrogen adsorption · Porous polymers · Polymer-silica composites . Porosimetry

\section{Introduction}

Cross-linked polymers having excellent porosity and unusually high bulk density, especially these in the form of spherical beads, are very attractive for many applications including adsorption and separation processes, supports for exchange of ionic compounds and catalysts, or carriers for drugs and immobilization of enzymes etc. (Kolarz et al. 2002; Oh et al. 2008; Li and Chase 2010; Grochowicz et al. 2013; Maciejewska and Kołodyńska 2015). Obviously, their application is closely related to both their chemical composition and microscale morphology. Therefore, much effort was directed towards the design and synthesis of new polymers with tailored properties (Horák et al. 2004; Grochowicz et al. 2008; Wu et al. 2012; Naghash and Shafie 2013; Zaleski et al. 2015). A very interesting approach to the modification of the properties of preformed porous polymers is combining them with various inorganic species with technological importance such as silica gel, titania, zirconium oxide, and others (Suzuki et al. 2000; Kierys et al. 2010, 2013; Koubková et al. 2014). Polymer beads play a critical role in such polymer-inorganic composite materials by acting as supports, templates, or matrices. They may be assumed as a universal phase that allows deposition of an inorganic component with different appearance and physical properties. Furthermore, the interior of polymer beads can be considered as a reaction system ensuring a specific microenvironment where transformation of precursors of inorganic species takes place. Therefore, it might be expected that such a poly- 
mer-supported system in which significant isolation of space is achieved prevents inorganic nanoparticles from aggregation, which is very important for preserving their morphological properties. Since such polymer-supported systems possess a highly developed and complex internal pore structure, the determination of changes in the porosity of composite materials in the micro- and meso-scale, in comparison to the employed polymer support, is a crucial issue for their successful separation and application.

Positron porosimetry based on positron annihilation lifetime spectroscopy (PALS) is a highly suitable technique for thorough investigation of porosity changes in such polymer-supported systems, since it provides information about the system in conditions where it is used. Unlike the most common adsorption methods (i.e. the low-temperature gas sorption method or mercury porosimetry), positron porosimetry makes it possible to investigate materials without cooling thereof. In addition, a great advantage of this technique is undoubtedly the possibility to investigate any free volumes without using any adsorbate molecules. This is especially important in the case of polymer-supported samples because of their ability to swell in different solvents, both in gases and liquids. Moreover, this technique provides reliable information concerning changes in any free volumes with diameters below $2 \mathrm{~nm}$ up to several tens of nanometers. Its usefulness for investigation of various free spaces, which include mesopores (He et al. 2013; Hill et al. 2009), micropores (Kullmann et al. 2010), and even intermolecular free volumes (Zgardzińska and Goworek 2015) has already been recognized.

This work is focused on the correlation between structural parameters derived from the PALS technique and from the low-temperature nitrogen sorption for a series of polymersilica composites synthesized by the swelling of the preformed porous polymers in a silica precursor (tetraethylsilane, TEOS). Polymer- $\mathrm{SiO}_{2}$ composites were prepared using cross-linked polymers with different chemical composition and porosity (i.e. shape of pores and their connectivity) as a polymer support. The series of composites was synthesized at different $\mathrm{pH}$ and with different contents of silica species. Application of different polymer supports and processing conditions makes it possible to investigate their influence on the resulting properties of composite materials. Variation of such conditions changes the pore structure and arrangement of $\mathrm{SiO}_{2}$ deposits within a polymer support.

\section{Experimental}

\subsection{Materials}

Polymer resins Amberlite XAD7 (ROHM \& HAAS, denoted hereafter by the abbreviation XAD7), XAD4, and
XAD16 were supplied by Sigma Aldrich in the form of white insoluble beads, and they served as polymer supports. Prior to use, the beads were rinsed with distilled water and dried in air at $80{ }^{\circ} \mathrm{C}$ for at least $12 \mathrm{~h}$. Tetraethoxysilane (TEOS, $98 \%$ ) serving as a silica source, was supplied by Sigma-Aldrich and used as received.

\subsubsection{Synthesis of polymer-SiO ${ }_{2}$ composites using different polymer supports}

Polymer- $\mathrm{SiO}_{2}$ composites were synthesized according to the procedure described elsewhere (Krasucka et al. 2015). To synthesize the composites, dry polymer beads were soaked with TEOS so as to yield TEOS-swollen polymer beads. The maximum amount of absorbed TEOS was 2.1, 1.9 , and $0.8 \mathrm{~g}$ of TEOS per $1 \mathrm{~g}$ of XAD16, XAD7, and XAD4, respectively. Next, the TEOS-swollen beads were submerged in a $2 \mathrm{M} \mathrm{HCl}$ solution $(100 \mathrm{~mL} / 1 \mathrm{~g})$ and left for $24 \mathrm{~h}$ at room temperature. The solid product was separated, rinsed with water, dried at $80^{\circ} \mathrm{C}$, and labeled as XAD4$\mathrm{SiO}_{2}, \mathrm{XAD} 16-\mathrm{SiO}_{2}$, and XAD7-SiO , respectively.

\subsubsection{Synthesis of XAD7-SiO ${ }_{2}$ composite samples with different $\mathrm{SiO}_{2}$ contamination}

XAD7- $\mathrm{SiO}_{2}$ composite samples with different $\mathrm{SiO}_{2}$ contamination were obtained by soaking with the TEOS solution at different concentrations of anhydrous ethanol. Ethanol was used as a good solvent for TEOS to facilitate total filling of pores and homogeneous distribution of TEOS within the polymer beads. The maximum amount of TEOS introduced into $1 \mathrm{~g}$ of the polymer support by swelling was as follows: 0.0024, 0.0048, 0.0072, and $0.0091 \mathrm{~mol}$. After $6 \mathrm{~h}$ of equilibration, swollen XAD7 beads were dried for $6 \mathrm{~h}$ at $80{ }^{\circ} \mathrm{C}$. Next, gelation of $\mathrm{SiO}_{2}$ was conducted in a water solution of $\mathrm{HCl}$ at $\mathrm{pH} 0.44$. Then, the beads were rinsed with water, and again dried at $80{ }^{\circ} \mathrm{C}$. The resulting $\mathrm{XAD7}-\mathrm{SiO}_{2}$ composites were denoted as XAD7-SiO ${ }_{2} @ 12 w t \%, \quad X A D 7-S_{2}{ }_{2} @ 22 w t \%, \quad X A D 7-$ $\mathrm{SiO}_{2} @ 30 w t \%$, and $\mathrm{XAD7}-\mathrm{SiO}_{2} @ 35 \mathrm{wt} \%$. The number in the name of the composites presents the $\mathrm{SiO}_{2}$ contamination (wt $\%)$ in a given sample, taking into account the total mass of the polymer- $\mathrm{SiO}_{2}$ composite.

\subsubsection{Synthesis of XAD7- $\mathrm{SiO}_{2}$ composite samples at various $p H$}

The procedure was begun with soaking the XAD7 beads with TEOS. Next, the TEOS-swollen XAD7 beads were divided into four parts, and each group was immersed submerged in a water solution of $\mathrm{HCl}$ with an appropriate $\mathrm{pH}$ (i.e. $0.44,2,5$ and 9) and left for $24 \mathrm{~h}$ at room temperature. After $24 \mathrm{~h}$, the solid product was rinsed with 
water and dried at $80{ }^{\circ} \mathrm{C}$. The composites were labelled as follows: XAD7-SiO ${ }_{2} @ \mathrm{pH} 0.44, \mathrm{XAD7}-\mathrm{SiO}_{2} @ \mathrm{pH} 2, \mathrm{XAD} 7-$ $\mathrm{SiO}_{2} @ \mathrm{pH} 5$, and XAD7-SiO ${ }_{2} @ \mathrm{pH}$.

\subsection{Measurements}

\subsubsection{Nitrogen adsorption}

Nitrogen adsorption measurements $\left(\mathrm{LN}_{2}\right)$ were carried out with a volumetric method at $77 \mathrm{~K}$ using an automated sorption analyzer ASAP 2045 (Micromeritics, Norcros, GA). The samples were dried overnight at $80{ }^{\circ} \mathrm{C}$ under vacuum before the sorption experiment. The pore size distributions (PSDs) were determined using the BJH procedure (Barrett et al. 1951). The total pore volumes were estimated from a single point adsorption at $0.985 \mathrm{p} / \mathrm{p}_{0}$.

\subsubsection{Positron porosimetry}

The PALS technique uses positrons emitted to the material from a radioactive source. Encountering electrons from the medium, the positrons annihilate with them or, alternatively, they form positronium, which is also unstable due to the annihilation process. Positronium is a bound, quasistable state of positron and electron that can be considered a hydrogen-like pseudo-atom, in which both particles, i.e. the positron and electron, orbit around a common center of mass. Because of the mutual spin orientations of these particles, two states of positronium can occur. The singlet state called para-positronium (p-Ps) annihilates intrinsically with a lifetime of $125 \mathrm{ps}$; this does not substantially depend on its surroundings. The lifetime of the triplet state called ortho-positronium (o-Ps) in vacuum is $142 \mathrm{~ns}$. However, inside the material, the positron bound in o-Ps can annihilate with one of the electrons from the surrounding medium. This process, called pick-off, results in shortening of the o-Ps lifetime and its probability depends on the size of the free volume in which o-Ps is located. The relation between a pore size and an o-Ps lifetime is described by the Extended Tao-Eldrup (ETE) model (Ciesielski et al. 1998). In this model, the pore is treated as a potential well, where ortho-positronium can occupy either a ground or an excited state of a particle in the well.

In order to conduct the PALS measurements, the $0.5 \mathrm{MBq}{ }^{22} \mathrm{Na}$ positron source was surrounded with the sample and placed inside a vacuum chamber. The turbomolecular pump provided the pressure of $10^{-5} \mathrm{~Pa}$. The positron annihilation lifetime spectra were collected using a standard "fast-slow" delayed coincidence spectrometer, equipped with two $\mathrm{BaF}_{2}$ scintillation detectors. The first one (crystal with size $\Phi 1 \times 1.5$ "), called "start", was intended to collect gamma quanta corresponding to the creation of positrons inside the source, while the second one (crystal with size $\Phi 1 \times 1$ "), called "stop", had the task of collecting quanta corresponding to the annihilation of either free positrons or positronium inside the sample. The apparatus was adjusted to conduct measurement of samples that had a wide range of free volume sizes. Therefore, the time range of the time-to-amplitude converter was $2 \mu \mathrm{s}$, thus the time width of a single channel of the multichannel analyzer was 116.3 ps. In order to collect the low energy gamma quanta from three-gamma annihilation of o-Ps, the stop energy window was widely open. This resulted in a relatively wide time resolution curve $(\mathrm{FWHM} \sim 350 \mathrm{ps})$. The number of coincidences was ca. $2 \times 10^{6}$ per hour.

The PALS spectra were analyzed with the use of the MELT program (Shukla et al. 1993) and, as a result, a positron/positronium lifetime distribution was obtained for each sample. The pore size distributions were calculated (Goworek et al. 2010) from the lifetime distributions, with the assumption that the pore shape was cylindrical. Because of the various types of surrounding of o-Ps trapped inside a free volume, various values of the $\Delta$ parameter related to the electron density of solids were assumed in the ETE calculations. For a pure polymer, the $\Delta$ value was $0.15 \mathrm{~nm}$, the same as the one previously obtained for the VP-DVB copolymer, which is similar to XAD4 and XAD16 (Zaleski et al. 2009) as well as for silica surface functionalized with $-\mathrm{CH}_{3}$ groups (He et al. 2007). A quite similar $\Delta$ value was also estimated for XAD7 (Gorgol et al. 2012). The presence of silica inside the composite particles results in the $\Delta$ value increase. The value of $0.16 \mathrm{~nm}$, calculated for $\mathrm{XAD7}-\mathrm{SiO}_{2}$ (Gorgol et al. 2012), was assumed for all composite samples.

\section{Results and discussion}

\subsection{Various polymer supports}

Different porous polymers were chosen as supports to verify their influence on the properties of the resulting polymer- $\mathrm{SiO}_{2}$ composites. In this experiment, two of the selected polymers, XAD4 and XAD16, have the same chemical composition, but they differ in the pore size. In turn, the second pair, XAD4 and XAD7, exhibits similar porosity, but the chemical character of their skeletons is different, i.e. XAD4 is hydrophobic and XAD7 is moderately polar. The differences between the porosity of these supports determined from the nitrogen adsorption studies have previously been presented (Krasucka et al. 2015). As indicated by the shape of nitrogen isotherms and extended hysteresis loops, these polymers exhibit high heterogeneity of the pore sizes, with not very distinctive peaks at their large size limit (left segment of Fig. 1). Moreover, the shape of the hysteresis loops indicates that the openings of 
Fig. 1 Pore size distributions calculated using the BJH method from the desorption branches of nitrogen isotherms (left) and obtained from positron porosimetry (right) for the polymer-SiO $\mathrm{S}_{2}$ composites (solid line) and polymer supports (dashed line) given in the figure

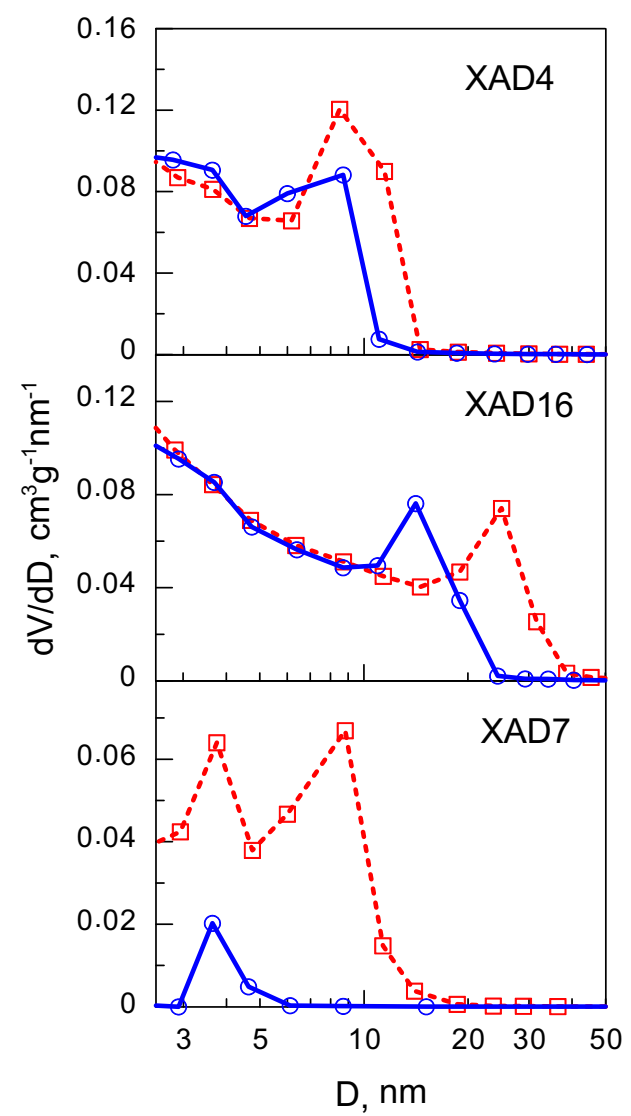

pores are smaller than their internal diameter. As mentioned above, the pore size distributions of XAD4 and XAD7 are similar while the pore sizes of XAD16 are ca. three times larger.

The introduction of silica into polymer supports affects their pore structure to a different extent. Less pronounced changes are observed for the $\mathrm{XAD} 4-\mathrm{SiO}_{2}$ composite, where only a slight decrease in the maximum pore size is observed. However, the silica presence in this material is half of the total pore volume (from 1.27 to $0.66 \mathrm{~cm}^{3} / \mathrm{g}$ ). This result evidences that the introduction of $\mathrm{SiO}_{2}$ causes elimination of the largest mesopores only partially. Probably, some of the pores were completely closed during the composite synthesis, while some of them remained completely free of silica. On the contrary, the maximum size of pores in $\mathrm{XAD} 16-\mathrm{SiO}_{2}$ is greatly reduced compared to the initial XAD16 polymer, whereas the total pore volume decreases only by ca. $20 \%$ (from 1.96 to $1.43 \mathrm{~cm}^{3} / \mathrm{g}$ ). Thus, it can be assumed that, unlike the $\mathrm{XAD} 4-\mathrm{SiO}_{2}$ composite, the largest pores of $\mathrm{XAD} 16-\mathrm{SiO}_{2}$ are only partially filled, which results in the reduction in their size. The greatest difference of PSD is observed between XAD7 and the $\mathrm{XAD} 7-\mathrm{SiO}_{2}$ composite. Surprisingly, the reduction of the total pore volume is only one-third (from 0.68 to $0.45 \mathrm{~cm}^{3}$ / g) after $\mathrm{SiO}_{2}$ introduction. Such porosity changes are related to the chemical character of the XAD7 support. Due to its moderately polar character, XAD7 exhibits fairly high affinity to TEOS, and in turn, contributes to high TEOS uptake during soaking (Krasucka et al. 2015). On the other hand, with their hydrophobic character, XAD4 and XAD16 exhibit low affinity to TEOS, and thus, its penetration of these matrices is limited. Obviously, the placement of silica gel within the polymer support determines the TEOS penetration. Thus, in contrast to other composites, it is assumed that silica condensation occurs within the polymer network, i.e. between polymer chains. It causes swelling of the polymer and, as a result, closing of the pores.

The results obtained by positron porosimetry (right segment of Fig. 1) reproduce the differences between PSDs for the polymer templates and the corresponding composites, which were observed in the nitrogen adsorption experiment. There is practically no change of the pore size in $\mathrm{XAD} 4-\mathrm{SiO}_{2}$ in comparison to its template. In turn, the pores of both $\mathrm{XAD} 16-\mathrm{SiO}_{2}$ and $\mathrm{XAD7}-\mathrm{SiO}_{2}$ composites are smaller and the PSD is narrower compared to the corresponding polymer supports. However, the change observed by positron porosimetry in the XAD7-based material is much smaller than the one shown by the nitrogen adsorption. Moreover, the consistency between both methods is only qualitative. The average pore sizes 
determined by PALS measurements are almost in all cases much smaller than those obtained from desorption branches of nitrogen isotherms.

Positron porosimetry does not allow determination of the absolute value of the pore volume, but it is possible to observe their relative changes. In the case of the studied pairs of the polymer-composite, the reduction of the total pore volume is ca. 10,0 , and $50 \%$ for $\mathrm{XAD} 4-\mathrm{SiO}_{2}$, $\mathrm{XAD} 16-\mathrm{SiO}_{2}$, and $\mathrm{XAD} 7-\mathrm{SiO}_{2}$, respectively. The simplest explanation for the discrepancy between PALS and $\mathrm{LN}_{2}$ results is the inability to detect the closed pores by nitrogen adsorption. This seems to be reasonable for $\mathrm{XAD} 4-\mathrm{SiO}_{2}$ and $\mathrm{XAD} 16-\mathrm{SiO}_{2}$, where positron porosimetry detects additional free volumes closed by the condensed silica and inaccessible for $\mathrm{N}_{2}$ molecules. However, the reduction of average pore sizes determined by PALS exceeds that produced by the nitrogen sorption, which cannot be explained easily. The greatest uncertainty in PALS calculations is the value of the $\Delta$ parameter. In this study, the $\Delta$ values were estimated on the basis of the temperature dependences (Gorgol et al. 2012). They can be slightly different for various materials, since $\Delta$ depends on the mean density and the composition of the pore walls. It is possible to set such a value of $\Delta$ that ensures the best fit of PALS results to the adsorption ones. However, in the case of the investigated composites, a $\Delta$ value of $0.20-0.25 \mathrm{~nm}$ has to be assumed to achieve good agreement with the $\mathrm{LN}_{2}$ results. This value is far beyond any value used for any material so far. Changing the pore geometry from cylindrical to spherical results in 35-40\% larger pore sizes obtained in the model. Nevertheless, even in this case, $\Delta=0.19-0.22 \mathrm{~nm}$ is required to match the $\mathrm{LN}_{2}$ results. Thus, it is unlikely that this single parameter is responsible for the disagreement of the pore sizes between both methods.

On the other hand, positron porosimetry based on the assumption that positronium (Ps) is trapped in a pore with a certain size is undoubtedly valid for closed pores. In the case of open ones, positronium can move from one pore to another. This is observed as e.g. positronium migration (Zaleski and Sokół 2011; He et al. 2012; Zaleski et al. 2013), which leads to underestimation of the volume of the smaller pores or prevents detection thereof at all. However, at room temperature, Ps has enough thermal energy to enter even relatively narrow interconnections between pores (Zaleski 2013). Thus, it is probable that, during its life, Ps travels through several pores with various sizes and its lifetime is determined by all these pores. In such a case, we would lose information about the smallest and the largest pores, because it is unlikely that Ps encounters only the smallest or the largest pores on its way. If this is the case, the width of PSD would rather provide information about the homogeneity of the sample, i.e. it will be wider if the sample has regions where small or large pores dominate.
The positronium mobility, which affects mostly the intensities of positronium components, can also be a source of distortions of the total pore volume. There is a high probability of positronium formation between polymer chains. Some of these interchain free spaces are open to mesopores. If Ps formed in such an interchain space enters a mesopore before its annihilation inside the polymer, it becomes indistinguishable from Ps formed on mesopore walls. This results in an increase in the mesopore-related component and, in consequence, in a larger volume of mesopores estimated using positron porosimetry. Therefore, filling interchain spaces by silica (expected in XAD7$\mathrm{SiO}_{2}$ ) or covering their outlets (possible in XAD16-SiO should result in the total pore volume other than that expected for unmodified polymer walls.

It is interesting that the only result that exhibits quantitative consistency in average pore sizes between both methods was obtained for $\mathrm{XAD7}-\mathrm{SiO}_{2}$. It can be assumed that silica condensation within the interchain free spaces of XAD7 results in relatively smooth pore walls. On the other hand, this is the only material with a narrow PSD obtained from the nitrogen adsorption, which makes it the least susceptible to the effects of the pore size averaging described previously. Our further study will focus on the class of polymer-silica composite materials based on XAD7 to minimize distortions of the results of either method.

\subsection{Various amount of silica precursor}

An interesting problem concerning synthesis of composites is what amount of a silica precursor should be used to obtain a material with desired characteristics. A series of composites containing various amounts of silica species was studied. The same ratio of the TEOS ethanolic solution to the polymer was used during synthesis of these composites to keep the levels of polymer swelling as close as possible.

Until the $\mathrm{SiO}_{2}$ contamination within $\mathrm{XAD} 7-\mathrm{SiO}_{2}$ does not exceed $30 \mathrm{wt} \%$, the shape of the nitrogen isotherms of the composites (left segment of Fig. 2) resembles the shape observed for the pure polymer. The only differences are the broader hysteresis loop and the more pronounced step observed at $\mathrm{p} / \mathrm{p}_{0} \approx 0.5$ for $\mathrm{XAD7}-\mathrm{SiO}_{2} @ 22 \mathrm{wt} \%$ and $\mathrm{XAD7}-\mathrm{SiO}_{2} @ 30 w t \%$. The $\mathrm{N}_{2}$ isotherms change significantly when the silica content reaches $35 \mathrm{wt} \%$. They become a triangular $\mathrm{H} 2$ type with desorption at practically the same level above $\mathrm{p} / \mathrm{p}_{0}=0.5$. The PSDs of the composites calculated from the desorption branches of $\mathrm{N}_{2}$ isotherms exhibit bimodal distribution in all cases except the XAD7-SiO $@ 35 w t \%$ (right segment of Fig. 2). The first narrow peak appears at ca. $4 \mathrm{~nm}$, while the second one is very broad with a maximum around 6-8 nm. According 
Fig. 2 Low temperature nitrogen isotherms for adsorption (full symbols) and desorption (open symbols) (left) for the composites (solid line, circles) and the supporting polymer (dashed line, squares). The pore size distributions calculated using the BJH method from the desorption (open symbols) and adsorption (full symbols) branch of isotherms as well as those obtained from positron porosimetry (no symbols) (right) for different polymer- $\mathrm{SiO}_{2}$ composites synthesized with relative content of TEOS given in the figure



to Ref. (Reichenbach et al. 2011), such a shape of isotherms, i.e. shift of the desorption branch towards lower pressure and an almost vertical step at $\mathrm{p} / \mathrm{p}_{0}=0.46$, is caused by pore blocking and cavitation, respectively. However, both pore blocking and cavitation are relatively weakly present in the unmodified polymer and in XAD7$\mathrm{SiO}_{2} @ 12 \mathrm{wt} \%$. This is in agreement with the expected structure of XAD7, where pores formed between the polymer species (or polymer-silica species in the composite) are probably ink-bottle shaped with multiple necks. Pore blocking and cavitation becomes more distinct in XAD7-SiO $\mathrm{S}_{2} @ 22 \mathrm{wt} \%$ and $\mathrm{XAD7}-\mathrm{SiO}_{2} @ 30 \mathrm{wt} \%$. This indicates that the necks are narrower in comparison to XAD7-SiO $\mathrm{S}_{2} @ 12 \mathrm{wt} \%$. Finally, the segment of the isotherm characteristic for pore blocking disappears for XAD7$\mathrm{SiO}_{2} @ 35 \mathrm{wt} \%$. The sharp step remaining on the desorption branch seems to evidence that the cavitation effect is present alone. In accordance with the assumed interpretation, this would give information only about the size of the necks. This size is smaller than the critical size, below which all pores are emptied almost completely, regardless of their size, due to cavitation-induced evaporation. Therefore, the PSD of the ink-bottle pore bodies can be estimated only from the adsorption branch, and it should be very wide, reaching several tens of nanometers.

In this case, the already mentioned tendency to annihilate in the largest free volumes is a favorable property of positronium, which is used as a probe in positron porosimetry. This allows a presumption that, in contrast to nitrogen adsorption, positron porosimetry would rather detect pore interiors instead of the necks connecting them. Indeed, the average pore sizes obtained from positron porosimetry (right segment of Fig. 2) are larger compared to the narrow peak from the nitrogen desorption, which was ascribed to the pore necks. However, the PSDs derived from positron porosimetry hardly resemble distributions expected 
if they were determined from the adsorption branch. They are similar to the composites containing 12, 22, and $30 \mathrm{wt} \%$ of pure silica. All these PSDs have a maximum between 5 and $6 \mathrm{~nm}$ and they are 2-3 nm wide. The PSD obtained for XAD7- $-\mathrm{SiO}_{2} @ 35 w t \%$ has a similar width, but its maximum falls on $4 \mathrm{~nm}$ only. In fact, if we take into account the tendency of MELT analysis to underestimate the width of distribution (Zaleski 2006; Zaleski et al. 2009), the positron porosimetry results are closer to the second peak from the nitrogen desorption. Therefore, it is most likely that the PSDs represent the average size of the pore interiors and their necks due to positronium mobility (see previous section). The most interesting result from this series was obtained for XAD7$\mathrm{SiO}_{2} @ 35 \mathrm{wt} \%$. It exhibits almost perfect agreement between PSDs from nitrogen desorption and positron porosimetry.

It should be noticed that the total pore volume decreases with the increasing content of silica within the composites. The comparison of the total pore volume determined by nitrogen adsorption $\left(\mathrm{V}_{\mathrm{LN} 2}\right)$ and positron porosimetry ( $\mathrm{V}_{\text {PALS }}$ ) (including the results from the next section) reveals linear dependence between them. Fitting the linear function $\mathrm{V}_{\mathrm{LN} 2}=\mathrm{a} \mathrm{V}_{\text {PALS }}+\mathrm{b}$ to the experimental data resulted in finding $a=3.38 \pm 0.72 \mathrm{~cm}^{3} / \mathrm{g}$ and $\mathrm{b}=-0.03 \pm 0.01 \mathrm{~cm}^{3} / \mathrm{g}$. Such a simple calibration of the positron porosimetry results allows comparing the total pore volume measured by both techniques. The agreement between them is surprisingly good (Fig. 3).

\subsection{Various pH of TEOS condensation}

Another parameter that is expected to influence the pore structure of composites is the $\mathrm{pH}$ of the reacting mixture. This supposition is confirmed by the differences in nitrogen adsorption isotherms, which were measured for composites synthesized at various $\mathrm{pH}$ (left segment of Fig. 4). The triangular hysteresis of the $\mathrm{H} 2$ type is observed for samples synthesized in an acidic solution ( $\mathrm{pH} 0.44$ and 2), while it changes into parallelly oriented adsorption/desorption branches of the $\mathrm{H} 1$ type at $\mathrm{pH}$ 5. It is noteworthy that the isotherm of XAD7- $\mathrm{SiO}_{2} @ \mathrm{pH} 5$ does not exhibit any features that were ascribed previously to pore blocking or cavitation in the base polymer. Thus, we expect the pore structure of this composite to be highly altered in comparison to XAD7. Surprisingly, the isotherms of XAD7$\mathrm{SiO}_{2} @ \mathrm{pH} 9$ show no further changes in this direction. They greatly resemble the shape of the $\mathrm{N}_{2}$ isotherms of an unmodified polymer support.

The comparison of PSDs calculated according to the $\mathrm{BJH}$ procedure and obtained from positron porosimetry (right segment of Fig. 4) confirms our observations from the previous section. There is very good agreement between both methods for XAD7-SiO $@$ @H0.44 and $\mathrm{XAD7}-\mathrm{SiO}_{2} @ \mathrm{pH} 2$. Thus, there is no reason to suspect the



Fig. 3 The total pore volume determined by nitrogen adsorption and positron porosimetry for the polymer- $\mathrm{SiO}_{2}$ composites synthesized with various relative concentration of TEOS

presence of cavitation effects here. The broad PSD from the nitrogen adsorption is not reflected fully by the PSD given by the positron porosimetry for $\mathrm{XAD7}-\mathrm{SiO}_{2} @ \mathrm{pH} 5$. However, the result obtained by the positron porosimetry confirms that the pores in this composite are the largest (maximum of PSD placed at $7 \mathrm{~nm}$ and its width $>10 \mathrm{~nm}$ ) among all materials synthesized with the use of the XAD7 support. The most likely cause of the discrepancy between the results of both methods is the information averaging due to positronium travelling through pores having various sizes, as described in the previous sections. Positron porosimetry confirms the findings of the nitrogen adsorption that the mesopores remain practically the same in XAD7-SiO $2 @$ pH9 as in XAD7.

The agreement between the total pore volume measured using nitrogen adsorption and positron porosimetry for samples synthesized at various pH (Fig. 5) is not as good as in Fig. 3, but still the general trend is preserved by the results of both methods. The pores with the smallest total volume are obtained at low $\mathrm{pH}$. Then, the pore volume is almost doubled at $\mathrm{pH} 5$, and finally decreases to the intermediate value, observed for XAD7, at $\mathrm{pH} 9$.

\section{Conclusions}

The comparison of the results of positron porosimetry and nitrogen adsorption obtained for the series of samples, which consists of various polymers and corresponding composites, including the ones synthesized at various content of TEOS and at various $\mathrm{pH}$, shows a universal 
Fig. 4 Low temperature nitrogen isotherms for adsorption (full symbols) and desorption (open symbols) (left).

The pore size distributions calculated using the $\mathrm{BJH}$ method from the desorption branches (open symbols) and derived from positron porosimetry (no symbols) (right) for the polymer- $\mathrm{SiO}_{2}$ composites synthesized at $\mathrm{pH}$ given in the figure
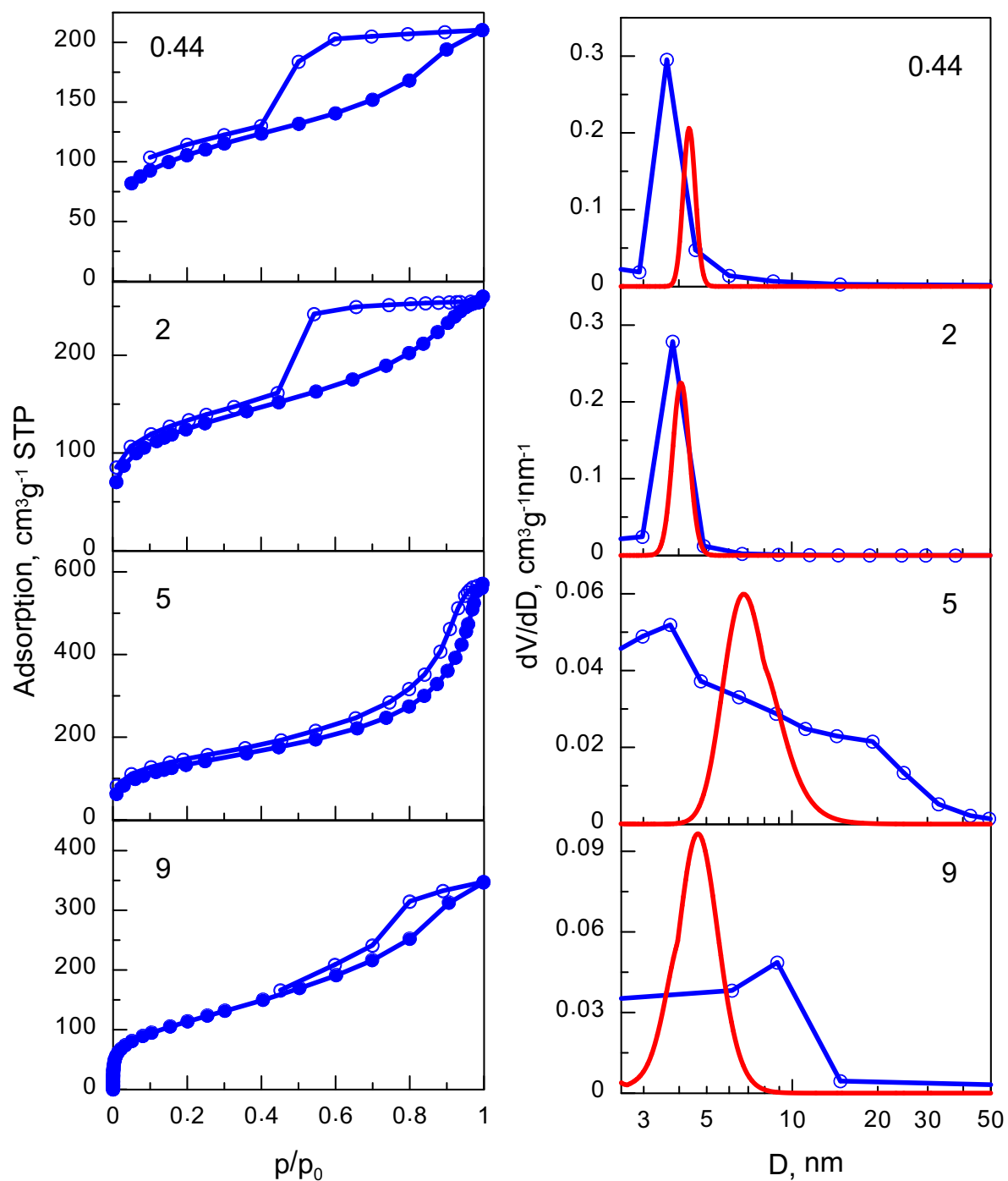

rule: the consistent pore sizes are obtained when the PSD given by nitrogen adsorption is narrow. Therefore, the most probable cause of the discrepancies between both methods is positronium mobility in the system of connected pores. Averaging of the positron porosimetry results, leading to underestimation of the contribution of the smallest and the largest pores, should be expected.

Inconsistencies can also be found for the volume of pores determined by both techniques for XAD4 and XAD16-based samples. The discrepancies can be a consequence of positronium escape from interchain spaces to mesopores, the rate of which changes if free volumes between polymer chains are filled or capped. However, the inconsistencies almost disappear in the case of XAD7based composites. These composites differ from other samples in the polymer structure "sealed" by silica condensed between polymer chains.
Taking into account the results of both methods, the greatest change in the pore size and their volume during composite synthesis occurred in XAD7. Hence, it seems that the chemical character of the material influences this process more than the size of polymer pores. Specifically, silica condensation in a polar material considerably affects porosity, which gives opportunity to tailor the structure of the resulting composite.

Both the content of the silica precursor in the liquid used during synthesis and $\mathrm{pH}$ have a significant impact on the resulting composite. The increase in the silica content results mostly in a decrease in the total pore volume. The pore size distribution remains similar to the initial polymer (mainly changes the maximum size of the pores), until reaching the $35 \mathrm{wt} \%$ of silica, when all pores larger than $5 \mathrm{~nm}$ disappear. Such a narrow pore size distribution is observed in composites synthesized with pure TEOS at 


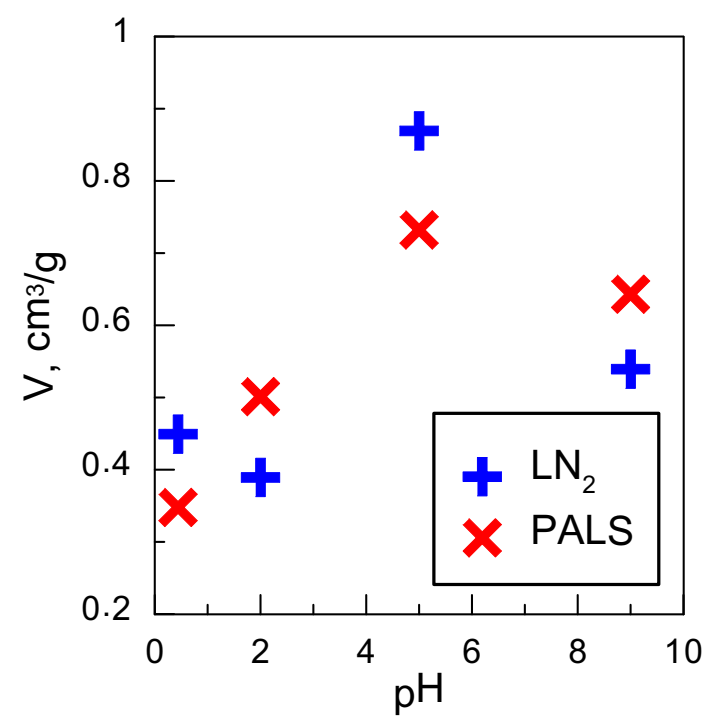

Fig. 5 The total pore volume determined by nitrogen adsorption and positron porosimetry for the polymer-silica composites synthesized at various $\mathrm{pH}$

highly acidic conditions. However, the composite synthesized at $\mathrm{pH} 5$ differs greatly from the other materials. It exhibits the broadest pore size distribution among all samples supported by XAD7. In contrast, the synthesis at $\mathrm{pH} 9$ retains the mesopore structure almost intact. Probably, the penetration of the mesopores by TEOS is highly suppressed there. This may be caused by faster silica condensation than that in other samples (due to basic conditions).

The positron porosimetry results do not confirm the pore blocking and cavitation mechanisms, which occur during nitrogen desorption in silicas. It seems that the desorption branch of isotherms allows calculation of actual pore sizes in these polymers and silica-polymer composites.

Acknowledgments This work was supported by Grant 2013/09/D/ ST2/03712 of the National Science Center in Poland.

Open Access This article is distributed under the terms of the Creative Commons Attribution 4.0 International License (http://crea tivecommons.org/licenses/by/4.0/), which permits unrestricted use, distribution, and reproduction in any medium, provided you give appropriate credit to the original author(s) and the source, provide a link to the Creative Commons license, and indicate if changes were made.

\section{References}

Barrett, E.P., Joyner, L.G., Halenda, P.P.: The determination of pore volume and area distributions in porous substances. I. Computations from nitrogen isotherms. J. Am. Chem. Soc. 73(1), 373-380 (1951). doi:10.1021/ja01145a126

Ciesielski, K., Dawidowicz, A.L., Goworek, T., Jasinska, B., Wawryszczuk, J.: Positronium lifetimes is porous Vycor glass.
Chem. Phys. Lett. 289(1-2), 41-45 (1998). doi:10.1016/S00092614(98)00416-3

Gorgol, M., Tydda, M., Kierys, A., Zaleski, R.: Composition of pore surface investigated by positron annihilation lifetime spectroscopy. Micropor Mesopor Mater. 163, 276-281 (2012). doi:10.1016/j.micromeso.2012.07.029

Goworek, J., Zaleski, R., Buda, W., Kierys, A.: Free volumes evolution during desorption of $\mathrm{n}$-heptane from silica with regular pore geometry. Positron annihilation study. Appl. Surf. Sci. 256(17), 5316-5322 (2010). doi:10.1016/j.apsusc.2009.12.069

Grochowicz, M., Bartnicki, A., Gawdzik, B.: Synthesis of a new tetrafunctional monomer, 1,4-di(2-hydroxy-3-methacryloyloxypropoxy)phenol, and its copolymerization. J. Appl. Polym. Sci. 107(6), 3718-3726 (2008). doi:10.1002/app.27531

Grochowicz, M., Gawdzik, B., Jaćkowska, M., Buszewski, B.: Thermal characterization of polymeric anion exchangers with a dendrimeric structure. J. Therm. Anal. Calorim. 114(3), 955-961 (2013). doi:10.1007/s10973-013-3096-1

He, C., Oka, T., Kobayashi, Y., Oshima, N., Ohdaira, T., Kinomura, A., Suzuki, R.: Positronium annihilation and pore surface chemistry in mesoporous silica films. Appl. Phys. Lett. 91(2), 024102-024103 (2007). doi:10.1063/1.2756310

He, C., Wang, S., Kobayashi, Y., Ohdaira, T., Suzuki, R.: Role of pore morphology in positronium diffusion in mesoporous silica thin films and in positronium emission from the surfaces. Phys. Rev. B 86(7), 075415 (2012). doi:10.1103/PhysRevB.86.075415

He, C., Xiong, B., Mao, W., Kobayashi, Y., Oka, T., Oshima, N., Suzuki, R.: On determining the entrance size of cage-like pores in mesoporous silica films by positron annihilation lifetime spectroscopy. Chem. Phys. Lett. 590, 97-100 (2013). doi:10. 1016/j.cplett.2013.10.042

Hill, M.R., Pas, S.J., Mudie, S.T., Kennedy, D.F., Hill, A.J.: Internal and external surface characterisation of templating processes for ordered mesoporous silicas and carbons. J. Mater. Chem. 19(15), 2215-2225 (2009)

Horák, D., Rittich, B., Španová, A.: Effect of reaction parameters on properties of dispersion-polymerized hydrophilic microspheres as supports for immobilization of proteins. In: Tauer, K. (ed.) Aqueous Polymer Dispersions. Progress in Colloid and Polymer Science, vol. 124, pp. 77-81. Springer, Berlin (2004)

Kierys, A., Buda, W., Goworek, J.: The porosity and morphology of mesoporous silica agglomerates. J. Porous Mater. 17(6), 669-676 (2010). doi:10.1007/s10934-009-9337-9

Kierys, A., Zaleski, R., Buda, W., Pikus, S., Dziadosz, M., Goworek, J.: Nanostructured polymer-titanium composites and titanium oxide through polymer swelling in titania precursor. Colloid Polym. Sci. 291(6), 1463-1470 (2013). doi:10.1007/s00396-0122881-x

Kolarz, B.N., Trochimczuk, A.W., Jermakowicz-Bartkowiak, D., Jezierska, J., Apostoluk, W.: Synthesis and some sorption properties of the anion-exchangers with biguanidyl groups. React. Funct. Polym. 52(1), 53-60 (2002). doi:10.1016/S13815148(02)00076-7

Koubková, J., Müller, P., Hlídková, H., Plichta, Z., Proks, V., Vojtěšek, B., Horák, D.: Magnetic poly(glycidyl methacrylate) microspheres for protein capture. New Biotechnol. 31(5), 482-491 (2014). doi:10.1016/j.nbt.2014.06.004

Krasucka, P., Stefaniak, W., Kierys, A., Goworek, J.: Polymer-silica composites and silicas produced by high-temperature degradation of organic component. Thermochim. Acta 615, 43-50 (2015). doi:10.1016/j.tca.2015.07.004

Kullmann, J., Enke, D., Thraenert, S., Krause-Rehberg, R., Inayat, A.: Characterization of nanoporous monoliths using nitrogen adsorption and positronium annihilation lifetime spectroscopy. Colloids Surf. A 357(1-3), 17-20 (2010). doi:10.1016/j.colsurfa.2009.09. 030 
Li, J., Chase, H.A.: Development of adsorptive (non-ionic) macroporous resins and their uses in the purification of pharmacologically-active natural products from plant sources. Nat. Prod. Rep. 27(10), 1493-1510 (2010). doi:10.1039/C0NP00015A

Maciejewska, M., Kołodyńska, D.: Synthesis and characterization of porous microspheres bearing pyrrolidone units. Mater. Chem. Phys. 149-150, 43-50 (2015). doi:10.1016/j.matchemphys.2014. 09.026

Naghash, H., Shafie, F.: Synthesis and characterization of a novel silane-based vinylic monomer and its application in the multilayer core-shell latex. Polym. Sci. Ser. B 55(11-12), 620-633 (2013). doi:10.1134/S1560090413130022

Oh, J.K., Drumright, R., Siegwart, D.J., Matyjaszewski, K.: The development of microgels/nanogels for drug delivery applications. Prog. Polym. Sci. 33(4), 448-477 (2008). doi:10.1016/j. progpolymsci.2008.01.002

Reichenbach, C., Kalies, G., Enke, D., Klank, D.: Cavitation and pore blocking in nanoporous glasses. Langmuir 27(17), 10699-10704 (2011). doi:10.1021/la201948c

Shukla, A., Peter, M., Hoffmann, L.: Analysis of positron lifetime spectra using quantified maximum-entropy and a general linear filter. Nucl. Instrum. Methods A 335(1-2), 310-317 (1993). doi:10.1016/0168-9002(93)90286-Q

Suzuki, T.M., Bomani, J.O., Matsunaga, H., Yokoyama, T.: Preparation of porous resin loaded with crystalline hydrous zirconium oxide and its application to the removal of arsenic. React. Funct. Polym. 43(1-2), 165-172 (2000). doi:10.1016/S13815148(99)00038-3
Wu, D., Xu, F., Sun, B., Fu, R., He, H., Matyjaszewski, K.: Design and preparation of porous polymers. Chem. Rev. 112(7), 3959-4015 (2012). doi: $10.1021 / \mathrm{cr} 200440 \mathrm{z}$

Zaleski, R.: Measurement and analysis of the positron annihilation lifetime spectra for mesoporous silica. Acta Phys. Pol. A 110(5), 729-738 (2006)

Zaleski, R.: Ortho-positronium localization in pores of Vycor glass at low temperature. J. Phys. 443(1), 012062 (2013). doi:10.1088/ 1742-6596/443/1/012062

Zaleski, R., Błażewicz, A., Kierys, A.: Ortho-positronium migration in mesopores of MCM-41, MSF and SBA-3. Nukleonika 58(1), 233-238 (2013)

Zaleski, R., Goworek, J., Maciejewska, M.: Positronium lifetime in porous VP-DVB copolymer. Phys. Status Solidi C 6(11), 2445-2447 (2009). doi:10.1002/pssc.200982075

Zaleski, R., Maciejewska, M., Puzio, M.: Mechanical stability of porous copolymers by positron annihilation lifetime spectroscopy. J. Phys. Chem. C 119(21), 11636-11645 (2015). doi:10.1021/acs.jpcc.5b01722

Zaleski, R., Sokól, M.: Influence of atmospheric gases present in the pores of MCM-41 on lifetime of ortho-positronium. Mater. Sci. Forum 666, 123-128 (2011). doi:10.4028/www.scientific.net/ MSF.666.123

Zgardzińska, B., Goworek, T.: Positronium in solid phases of n-alkane binary mixtures. Chem. Phys. 458, 62-67 (2015). doi:10.1016/j.chemphys.2015.06.002 